\title{
BC 90-19-34 and BC 93-16-43 Red Raspberries
}

\section{Michael Dossett ${ }^{1}$, Chaim Kempler, and Hugh Daubeny \\ Agriculture and Agri-Food Canada, Pacific Agri-Food Research Centre, P.O. Box 1000, Agassiz, British Columbia, V0M 1 A0 Canada}

Additional index words. Amphorophora agathonica, Phytophthora rubi, raspberry bushy dwarf virus, Rubus idaeus, Rubus strigosus, aphid resistance, root rot

BC 90-19-34 and BC 93-16-43 are red raspberry (Rubus idaeus L.) selections from the Agriculture and Agri-Food Canada, $\mathrm{Pa}$ cific Agri-Food Research Center (AAFCPARC) breeding program being released as germplasm available for breeding. These two selections are $F_{1}$ hybrids between wild North American red raspberry (Rubus strigosus Michx.) and 'Tulameen', which were initially selected for their combination of outstanding resistance to root rot caused by Phytophthora rubi [(Wilcox \& Duncan) Man in't Veld] and resistance to colonization by the aphid vector of the raspberry mosaic virus complex in North America, Amphorophora agathonica Hottes. Aphid resistance in these two selections is conferred by novel sources not yet found in any cultivars and that have not yet been overcome by any of the six biotypes of $A$. agathonica identified to date. In addition to being resistant to root rot and aphid colonization, BC 93-16-43 appears to also represent a novel source of resistance to pollen transmission of raspberry bushy dwarf virus (RBDV) conferred by its wild parent, Kanata-B. Root rot and raspberry bushy dwarf virus are two of the biggest disease issues limiting raspberry production around the world (Hall et al., 2009). In addition, aphid resistance is an important tool for combating aphidvectored viruses that may cause plant decline by themselves in some cases but can also exacerbate symptoms and spread of raspberry bushy dwarf virus in mixed infections because of increased titer levels (QuitoAvila and Martin, 2012; R. Martin, personal communication).

\footnotetext{
Received for publication 4 Mar. 2013. Accepted for publication 28 Mar. 2013.

This work was funded with support from Agriculture and Agri-Food Canada, the Raspberry Industry Development Council of British Columbia, the Washington Red Raspberry Commission, and the Lower Mainland Horticultural Improvement Association.

We gratefully acknowledge B. Harding, G. Kliever, and S. Nanni (Agriculture and Agri-Food Canada) as well as C.E. Finn (U.S. Department of Agriculture, Agricultural Research Service), P.P. Moore (Washington State University), and R. Honcoop (Randy Honcoop Farms) for their assistance in the evaluations of BC 90-19-34 and BC 93-16-43.

${ }^{1}$ To whom reprint requests should be addressed; e-mail Michael.Dossett@agr.gc.ca.
}

Although lacking the yield, fruit size, and firmness to merit commercial production in their own right, both selections have a very good aromatic flavor, good fertility for first-generation hybrids from wild plants, and have been valuable as parents in the AAFC-PARC breeding program because of their outstanding insect and disease resistance. BC 90-19-34 and BC 93-16-43 are being released because use of this germplasm should help breeding programs to broaden the base of resistance in existing elite lines while being able to recover the yield, fruit size, and/or firmness required for commercial production in one to two generations of backcrossing to complementary parents.

\section{Origin}

BC 90-19-34 is a selection from the 1990 cross of 'Tulameen' $\times$ BC 86-62-3, a wild $R$. strigosus seedling from seed collected near Lake George, MN (Fig. 1A). BC 8662-3 was initially selected for root rot resistance in a greenhouse trial of raspberry germplasm (Bristow et al., 1988). BC 9019-34 was selected in the greenhouse for resistance to the aphid A. agathonica during routine screening and was subsequently found to have inherited resistance to root rot from its wild parent during greenhouse inoculation and screening (Lévesque and Daubeny, 1999). Since it was first selected in 1993, BC 90-19-34 has been evaluated in a number of replicated and unreplicated multiplant trials at Abbotsford, British Columbia, Canada, the Washington State University Puyallup Research and Extension Center in Puyallup, WA, the North Willamette Research and Extension Center in Aurora, OR, and on a commercial raspberry grower's farm in Lynden, WA, as well as in a variety of greenhouse screenings for aphid and root rot resistance.

BC 93-16-43 is a selection from the 1993 cross of Kanata-B $\times$ 'Tulameen' (Fig. 1B). Kanata-B is a wild $R$. strigosus seedling from seed collected in a suburb of Ottawa, Ontario, Canada, and was first selected as an alternate source of aphid resistance conferred by dominant complementary genes designated $\mathrm{Ag}_{2}$ and $\mathrm{Ag}_{3}$ (Daubeny and Stary, 1982). BC 9316-43 has been evaluated as a single plant in the field at Abbotsford, British Columbia, Canada, continuously since 1997 as well as in several replicated greenhouse trials for root rot and aphid resistance.

\section{Performance and Description}

BC 90-19-34 and BC 93-16-43 produce canes that are spiny and have glandular hairs along their length. Overall, spine and hair density are much higher on the canes and petioles of BC 90-19-34 than on BC 93-1643 , which produces spines on the main portions of the cane of similar size and density to the industry standard 'Meeker'. The presence of glandular hairs is a trait that is inherited from $R$. strigosus and distinguishes them readily from most raspberry cultivars (Jennings, 1988).

The primocanes of both selections are erect; however, primocanes of BC 90-19-34 are less vigorous than those of $\mathrm{BC} 93-16-43$. Primocanes of BC 93-16-43 also have a conspicuous glaucous waxy pubescence, whereas those of BC 90-19-34 are nonwaxy. The waxy glaucous bloom on the canes is easily rubbed off, although it can usually be found persisting around the nodes of dormant canes, where it is most conspicuous. The dormant canes of BC 90-19-34 are dark brown in color, darker than the dormant canes of either 'Tulameen' or 'Chemainus', and have a very slight reddish tint. The dormant canes of BC 93-16-43 are a light golden brown color, being slightly darker in the sun-exposed portions, and are much lighter in color than those of either 'Chemainus' or 'Tulameen' while also lacking the grayish hue of dormant canes of 'Meeker'. Although the canes of BC 93-16-43 often show some cracking at the base, canes of BC 90-19-34 show minimal or no cracking. The leaves of BC 90-19-34 are a dark green color, whereas the leaves of BC 93-16-43 are a light medium green color; both have five pinnately compound leaflets on primocanes and ternate leaflets on floricanes.

The fruiting laterals of $\mathrm{BC} 90-19-34$ are not particularly vigorous in comparison with other raspberries and hang straight out or slightly down. Despite this, lateral angle does not appear to interfere with mechanical harvesting of fruit, and fruit of BC 90-19-34 detach readily when machine-harvested and maintain good cohesion despite their softness. Fruit of BC 93-16-43 also detach readily, although they have not been evaluated for machine harvestability and it is unknown whether the soft fruit will maintain their cohesion through the process.

BC 90-19-34 and BC 93-16-43 have very good aromatic flavor with the soluble solids content of BC 90-19-34 being similar to, or slightly lower than, standard cultivars (Table 1). BC 90-19-34 also has a relatively long harvest season, similar in length and timing to its parent, 'Tulameen' (Table 1). Casual observations indicate that BC 93-1643 has a similar harvest season. Yields of BC 90-19-34 are low when compared with most commercial cultivars grown in the Pacific Northwest. This is likely a reflection, in part, of its small fruit size (Table 1). BC 93-16-43 
has not been planted in replicated trials for direct comparison, but has been noted for consistently producing fruit that are smaller and lighter/brighter in color than BC 90-1934, which has a similar color to 'Meeker', the commercial standard in the Pacific Northwest (Fig. 2). The small fruit size and soft texture are not unexpected for $F_{1}$ seedlings derived from wild $R$. strigosus. Despite this, these selections represent the best fertility and quality in the $F_{1}$ populations from which they were selected, and both selections have proven capable of producing progeny with acceptable size and firmness for the commercial processing industry in crosses where they have been used as parents by the AAFC-PARC breeding program (data not shown).

\section{Disease and Insect Reactions}

The outstanding characteristic of $\mathrm{BC} 90$ 19-34 and BC 93-16-43, which merit their release as germplasm, is their level of insect and disease resistance from novel sources. Lévesque and Daubeny (1999) were the first

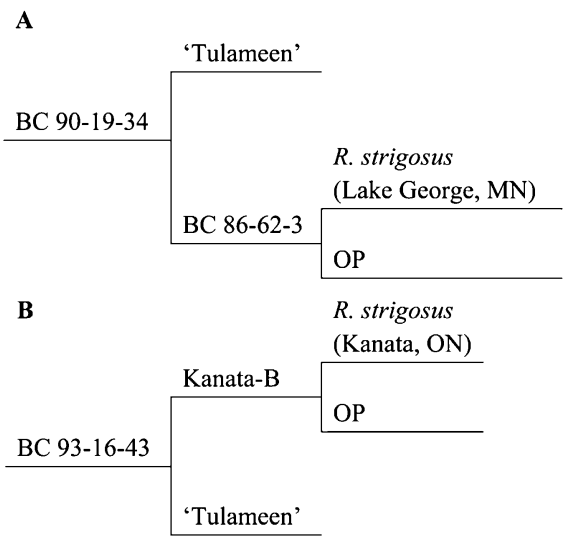

Fig. 1. Pedigrees of (A) BC 90-19-34 and (B) BC 93-16-43 red raspberries. Both are $\mathrm{F}_{1}$ hybrids between 'Tulameen' and selections of the wild North American red raspberry, Rubus strigosus. to demonstrate resistance to root rot caused by $P$. rubi in BC 90-19-34. Kempler et al. (2012) also noted that BC 90-19-34, and several of its progenies, had good resistance to root rot in greenhouse trials, ranking similarly to 'Latham', a cultivar widely recognized for its resistance. An unreplicated plot of BC 90-19-34, planted in a field naturally infected with the pathogen in Puyallup, WA, in 2001, also showed good vigor on evaluation in 2003 and 2004 (C. Kempler, personal observation; P. Moore, personal communication). BC 93-16-43 has not been planted in a field with root rot disease pressure; however, it has been tested extensively for root rot resistance in controlled inoculations in the greenhouse. In the late winter and early Spring of 2012, BC 93-16-43 was tested in five separate root rot trials in the greenhouse, each consisting of between seven and 10 replications. In each of these trials, BC 93-16-43 was compared with known resistant ('Latham') and susceptible ('Malahat') standards in addition to many other genotypes using the procedures described by Kempler et al. (2012). Consistently, through the course of these screens, BC 93-16-43 was one of the top performers and had a similar rating of disease symptoms to 'Latham' (Table 2). It is worth noting that comparisons between field and greenhouse screenings for root rot in raspberry have varied between showing good (Hoashi-Erhardt et al., 2008) and poor (Graham et al., 2011) correlation to field results with mixed reports regarding which is likely to produce a more severe disease reaction (Graham et al., 2011; Hoashi-Erhardt et al., 2008; Pattison et al., 2004). Because of the myriad of reasons why greenhouse screenings may produce different results from field plantings, it is recommended that the performance of both selections be assessed locally on diseased field sites to be certain that the observed resistance is effective against local isolates and in other environments.

BC 90-19-34 and BC 93-16-43 were initially noted for their resistance to the raspberry aphid $A$. agathonica during routine screening of seedlings. It was assumed that resistance in BC 90-19-34 was conferred by $A g_{I}$ from 'Tulameen' (Daubeny and Anderson, 1991) and that resistance in BC 93-16-43 was from either $A g_{1}$ or from the dominant complementary genes $\mathrm{Ag}_{2}$ and $\mathrm{Ag}_{3}$ identified in Kanata-B by Daubeny and Stary (1982). In 1990, an $\mathrm{Ag}_{1}$-breaking biotype of $\mathrm{A}$. agathonica was first identified (Daubeny and Anderson, 1991). More recently, six biotypes of $A$. agathonica have been identified (Dossett and Kempler, 2012). However, it is not known which biotype was used in the original screening of these selections as seedlings. During regular inspections since being selected, aphids have not been observed colonizing either BC $90-19-34$ or BC $93-16-43$ in the field. In addition, greenhouse assays have shown that BC 90-19-34 and BC 93-16-43 are resistant to all six biotypes of $A$. agathonica that have been identified to date and should be valuable as parents for aphid resistance (Dossett and Kempler, 2012).

BC 90-19-34 has been found to be susceptible to pollen transmission of RBDV in the field, testing positive by enzyme-linked immunosorbent assay (ELISA) in separate plantings in 2008 and 2009 in Abbotsford. In contrast, BC 93-16-43 has never tested positive for RBDV despite yearly ELISA testing and continuous exposure in the field since 1997. Although it is possible that BC 93-1643 is susceptible to pollen transmission of the virus and has merely escaped infection, none of its 10 sibs and half-sibs derived from Kanata-B have acquired the virus despite high infection rates in neighboring plants and continuous exposure at the PARC Abbotsford substation since 1997. The other parents of these 10 selections ('Tulameen' and 'Chilliwack') are both susceptible to the virus. As such, we believe that BC 93-16-43 most likely has resistance to pollen transmission of RBDV conferred by its wild parent, Kanata-B.

Since being selected in the mid-1990s, BC 90-19-34 and BC 93-16-43 have been rated subjectively, on a yearly basis, for incidence and severity of spur blight caused

Table 1. Yield, fruit weight, harvest season, and fruit traits of BC 90-19-34 and Pacific Northwest red raspberry cultivars. ${ }^{\mathrm{z}}$

\begin{tabular}{|c|c|c|c|c|c|c|c|c|}
\hline Clone & $\begin{array}{l}\text { Total yield } \\
(\mathrm{kg} / \mathrm{hill})\end{array}$ & $\begin{array}{l}\text { Fruit wt } \\
(\mathrm{g})^{\mathrm{y}}\end{array}$ & $\begin{array}{l}5 \% \text { harvest } \\
\text { (date) }\end{array}$ & $\begin{array}{c}50 \% \text { harvest } \\
\text { (date) }\end{array}$ & $\begin{array}{l}95 \% \text { harvest } \\
\text { (date) }\end{array}$ & $\begin{array}{l}\text { Harvest duration } \\
\text { (days) }\end{array}$ & $\begin{array}{l}\text { Fruit firmness }{ }^{\mathrm{x}} \\
(\mathrm{N})\end{array}$ & $\begin{array}{l}\text { Percent soluble } \\
\text { solids }^{w}\end{array}$ \\
\hline$\overline{\mathrm{BC}} 90-19-34$ & 2.64 & 2.95 & 10 July & 24 July & 10 Aug. & 32 & 1.16 & 10.5 \\
\hline Cascade Bounty & 2.87 & 3.63 & 8 July & 19 July & 8 Aug. & 32 & 1.33 & 9.9 \\
\hline Cascade Delight & 4.11 & 4.87 & 12 July & 20 July & 5 Aug. & 25 & 3.56 & 11.3 \\
\hline Chemainus & 3.20 & 3.77 & 6 July & 17 July & 2 Aug. & 27 & 2.42 & 10.8 \\
\hline Cowichan & 2.94 & 4.34 & 6 July & 16 July & 31 July & 25 & 2.06 & 10.1 \\
\hline Malahat & 3.03 & 4.18 & 30 June & 11 July & 30 July & 30 & 1.99 & 11.4 \\
\hline Meeker & 3.98 & 3.27 & 8 July & 19 July & 2 Aug. & 26 & 2.21 & 11.6 \\
\hline Qualicum & 4.34 & 4.62 & 8 July & 18 July & 1 Aug. & 26 & 2.87 & 11.7 \\
\hline Saanich & 4.60 & 3.26 & 6 July & 15 July & 3 Aug. & 28 & 2.23 & 11.2 \\
\hline Tulameen & 4.15 & 4.74 & 9 July & 20 July & 8 Aug. & 31 & 2.12 & 12.6 \\
\hline $\operatorname{LSD}^{\mathrm{v}}$ & 1.13 & 0.52 & 2 & 4 & 3 & 3 & 0.67 & 1.3 \\
\hline
\end{tabular}

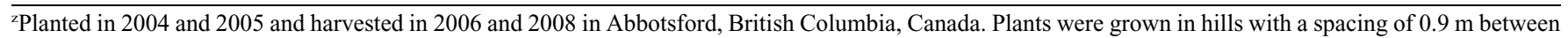
the plants and row spacing of $3 \mathrm{~m}$ (3588 plants/ha) and were pruned to six canes per hill and topped to a height of $1.5 \mathrm{~m}$.

${ }^{y}$ Weighted average based on mass of 50 randomly selected fruit at each harvest date.

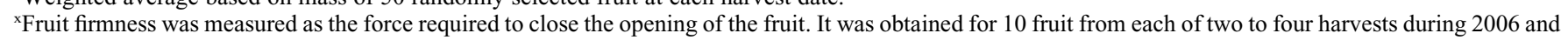
2008.

wBased on average of 10 fruit from each of two to four harvests during 2006 and 2008.

'Data were subjected to analysis of variance with least significant difference (LSD) of 5\% used to separate means. 
by Didymella applanata (Niessl) Sacc., cane botrytis caused by Botrytis cinerea (Pers.: Fr.), and cane spot caused by Elsinoë veneta (Burk.) Jenkins. In three-plant replicated plots evaluated over nine trial $\times$ year combinations, BC 90-19-34 had the lowest incidence of spur blight and cane botrytis when compared with cultivars from the Pacific Northwest (Table 3). BC 90-19-34 also had a low incidence of cane spot and was significantly lower than 'Malahat' or 'Qualicum'. BC 9316-43 has been observed to have a very low incidence of all three of these diseases; however, these observations are of only a single plant during this period, so the potential for these diseases may be higher (Table 3).

\section{Breeding Behavior}

BC 90-19-34 and BC 93-16-43 have been used extensively as parents for root rot resistance in the AAFC-PARC breeding program and a number of their progeny rate highly for root rot resistance (Kempler et al., 2012). In crosses with 'Malahat' (heterozygous for gene $A g_{1}$ ) to study segregation of aphid resistance, it was found that progeny of BC 93-16-43 $\times$ 'Malahat' segregated 3:1 for resistance to $A$. agathonica biotype $\mathrm{B}$ and $1: 1$ to biotypes $E$ and $F$ (Table 4 ). This is consistent with the hypothesis that BC 93-1643 carries a single dominant gene conferring resistance to all six biotypes (A to $\mathrm{F}$ ) of A. agathonica identified to date and does not fit the $\mathrm{Ag} 2 / \mathrm{Ag} 3$ model proposed by Daubeny and Stary (1982) for its parent, Kanata-B. At this time, further study is needed to confirm whether one or two loci are involved in conferring this resistance.

Seedlings of the cross 'Malahat' $\times$ BC 90-19-34 also segregated for resistance to A. agathonica biotypes $\mathrm{B}, \mathrm{E}$, and $\mathrm{F}$. In this case, resistance to biotype B segregated $7: 1$, whereas resistance to biotypes $\mathrm{E}$ and $\mathrm{F}$ segregated 1:1 (Table 4). This is consistent with the hypothesis that BC 90-19-34 is heterozygous for $A g_{1}$ from 'Tulameen', which confers resistance to biotypes A and B as well as an additional single dominant resistance allele at a separate locus conferring resistance to biotypes A to $\mathrm{F}$ inherited from its wild parent, $\mathrm{BC}$ 86-62-3.

In addition to conferring root rot resistance and multiple sources of aphid resistance to its progenies, BC 90-19-34 is heterozygous for gene $s$ (Lewis, 1939), which it has inherited from 'Tulameen'. Crosses with other genotypes carrying gene $s$ result in progenies segregating for spinelessness (data not shown).

\section{Availability}

Nuclear stock of BC 90-19-34 and BC 9316-43 has been tested by ELISA for RBDV and by polymerase chain reaction for raspberry latent virus, raspberry leaf mottle virus, black raspberry necrosis virus, and Rubus yellow net virus with negative results for each. BC 90-19-34 and BC 93-16-43 have been donated to the AAFC Canadian Clonal Germplasm Repository in Harrow, Ontario,

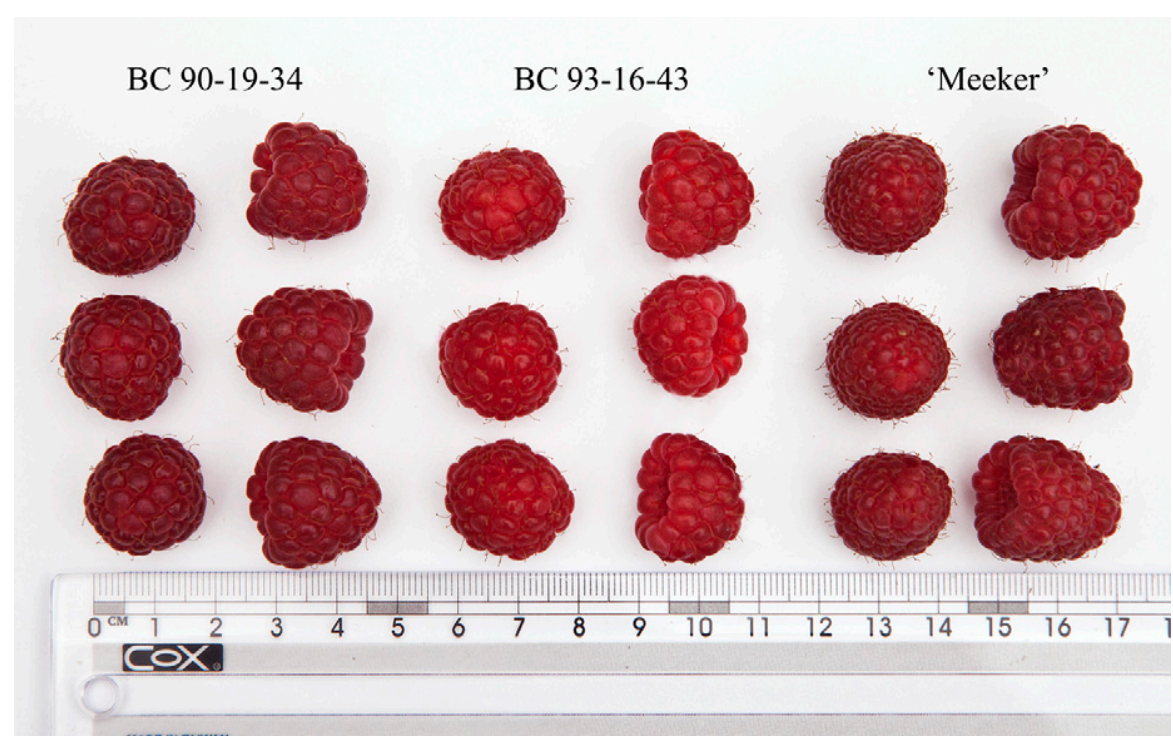

Fig. 2. Representative fruit of BC 90-19-34, BC 93-16-43, and the commercial standard 'Meeker' showing differences in size and color.

Table 2. Reaction of BC 93-16-43 and five raspberry cultivars to controlled greenhouse inoculation with Phytophthora rubi. ${ }^{\mathrm{z}}$

\begin{tabular}{|c|c|c|c|c|}
\hline & \multicolumn{2}{|c|}{ Inoculated } & \multicolumn{2}{|c|}{ Uninoculated Control } \\
\hline & Root rating ${ }^{\mathrm{y}}$ & Shoot rating ${ }^{x}$ & Root rating & Shoot rating \\
\hline$\overline{\mathrm{BC}} 93-16-43$ & 2.2 & 1.0 & 2.1 & 1.0 \\
\hline Cascade Bounty & 2.6 & 1.0 & 2.4 & 1.0 \\
\hline Cowichan $^{\mathrm{w}}$ & 6.7 & 1.8 & 2.1 & 1.0 \\
\hline Malahat & 6.8 & 2.1 & 2.3 & 1.0 \\
\hline Meeker & 6.3 & 2.0 & 2.0 & 1.0 \\
\hline Latham & 1.7 & 1.0 & 1.8 & 1.0 \\
\hline $\operatorname{LSD}^{\mathrm{v}}$ & 0.8 & 0.5 & $\mathrm{NS}^{\mathrm{u}}$ & NS \\
\hline
\end{tabular}

${ }^{\mathrm{z}}$ Based on five trials with seven to ten replications in each using the methods of Kempler et al. (2012).

${ }^{y}$ Average rating on a subjective 1 to 8 scale $(1=$ no visible darkening of roots, $8=$ roots completely dead $)$.

${ }^{\mathrm{x}}$ Average rating on a subjective 1 to 4 scale $(1=$ no visible disease symptoms, $4=$ shoot completely dead).

"Italicized entries indicate significant deviation of root and shoot ratings in inoculated plants from uninoculated controls based on Student's $t$ test.

${ }^{v}$ Data were subjected to analysis of variance with least significant difference (LSD) of 5\% used to separate means.

${ }^{\mathrm{u}_{\mathrm{NS}}}=$ No significant differences detected and mean separation not applicable.

Table 3. Cane disease ratings of BC 90-19-34 and BC 93-16-43 in comparison with Pacific Northwest red raspberry cultivars. ${ }^{\mathrm{z}}$

\begin{tabular}{lccc}
\hline & $\begin{array}{c}\text { Spur blight } \\
\text { (Didymella applanata) }\end{array}$ & $\begin{array}{c}\text { Cane botrytis } \\
\text { (Botrytis cinerea) }\end{array}$ & $\begin{array}{c}\text { Cane spot } \\
\text { (Elsinoë veneta) }\end{array}$ \\
\hline BC 90-19-34 & 2.2 & 1.1 & 1.3 \\
Cascade Bounty & 2.4 & 1.1 & 1.0 \\
Cascade Delight & 3.0 & 2.0 & 1.0 \\
Chemainus & 3.2 & 1.6 & 1.3 \\
Cowichan & 3.2 & 1.9 & 1.2 \\
Malahat & 3.3 & 1.4 & 2.6 \\
Meeker & 3.6 & 1.2 & 1.3 \\
Qualicum & 2.6 & 1.3 & 2.1 \\
Saanich & 2.3 & 1.3 & 1.4 \\
Tulameen & 2.7 & 1.6 & 1.4 \\
LSD & 0.5 & 0.5 & 0.5
\end{tabular}

Unreplicated plot from adjacent planting ${ }^{\mathrm{x}}$

BC 93-16-43 1.2

1.0

1.0

${ }^{\mathrm{z}}$ Data based on means of three-plant plots planted in replicated trials in 1996, 2000, 2004, and 2005 and evaluated in 2001, 2002, 2004, 2007, 2008, and 2009 for a total of nine trial $\times$ year combinations and rated on a subjective 1 to 4 scale $(1=$ no visible disease, $4=$ severe symptoms $)$.

${ }^{y}$ Data were subjected to analysis of variance with least significant difference (LSD) of $5 \%$ used to separate means.

${ }^{\mathrm{x}}$ Included for illustrative purposes only; not subjected to statistical analysis or intended for mean comparison. 
Table 4. Results of the $\chi^{2}$ test for goodness of fit to expected segregation ratios for aphid resistance to Amphorophora agathonica biotypes B, E, and F in raspberry seedlings of BC 93-16-43 $\times$ 'Malahat' and 'Malahat' $\times$ BC 90-19-34.

\begin{tabular}{|c|c|c|c|c|c|c|c|c|c|c|}
\hline \multirow[b]{2}{*}{ Cross } & \multicolumn{5}{|c|}{ Biotype B } & \multicolumn{5}{|c|}{ Biotypes $\mathrm{E}$ and $\mathrm{F}$} \\
\hline & Resistant & Susceptible & Expected ratio & $\chi^{2}$ & $P$ & Resistant & Susceptible & Expected ratio & $\chi^{2}$ & $\bar{P}$ \\
\hline$\overline{\text { BC 93-16-43 } \times \text { Malahat }^{z}}$ & 163 & 61 & $3: 1$ & 0.44 & 0.59 & 96 & $92^{y}$ & $1: 1$ & 0.08 & 0.77 \\
\hline & & & $5: 3$ & 10.8 & 0.001 & & & $1: 3$ & 68.1 & 0 \\
\hline Malahat $\times$ BC 90-19-34 & 98 & 10 & $7: 1$ & 1.04 & 0.31 & 57 & 51 & $1: 1$ & 0.33 & 0.56 \\
\hline
\end{tabular}

${ }^{2}$ Results to screening gave good fit to a model where 'Malahat' is heterozygous for the resistance allele $A g_{1}$ and BC 93-16-43 is heterozygous for an unknown single dominant resistance allele other than $A g_{1}$. Italicized entries are the results of $\chi^{2}$ tests showing the lack of fit under the $A g_{2} / A g_{3}$ model proposed by Daubeny and Stary (1982).

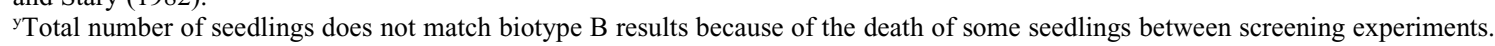

${ }^{x}$ Results to screening give good fit to a model where 'Malahat' is heterozygous for the resistance allele $A g_{1}$ and BC 90-19-34 is heterozygous for $A g_{1}$ and an additional single dominant resistance allele at a separate locus.

Canada, and the USDA-ARS National Clonal Germplasm Repository in Corvallis, OR, USA and may be available by contacting either. Limited quantities of plants or root cuttings of BC 90-19-34 and BC 93-16-43 may also be available from the Agriculture and Agri-Food Canada, Pacific Agri-Food Research Center, 6947 Highway \#7, Agassiz, British Columbia, V0M 1A0, Canada.

\section{Literature Cited}

Bristow, P.R., H.A. Daubeny, T.M. Sjulin, H.S. Pepin, R. Nestby, and G.E. Windom. 1988. Evaluation of Rubus germplasm for reaction to root rot caused by Phytophthora erythroseptica. J. Amer. Soc. Hort. Sci. 113:588-591.

Daubeny, H.A. and A. Anderson. 1991. 'Tulameen' red raspberry. HortScience 26:1336-1338.

Daubeny, H.A. and D. Stary. 1982. Identification of resistance to Amphorophora agathonica in the native North American red raspberry. J. Amer. Soc. Hort. Sci. 107:593-597.

Dossett, M. and C. Kempler. 2012. Biotypic diversity and resistance to the raspberry aphid Amphorophora agathonica in Pacific Northwestern North America. J. Amer. Soc. Hort. Sci. 137:445-451.

Graham, J., C.A. Hackett, K. Smith, M. Woodhead, K. Mackenzie, I. Tierney, D. Cooke, M. Bayer, and N. Jennings. 2011. Towards an understanding of the nature of resistance to Phytophthora root rot in red raspberry. Theor. Appl. Genet. 123:585-601.

Hall, H., K.E. Hummer, A. Jamieson, S. Jennings, and C. Weber. 2009. Raspberry breeding and genetics. Plant Breed. Rev. 32:39-382.

Hoashi-Erhardt, W.K., P.P. Moore, G.E. Windom, and P.R. Bristow. 2008. Field and greenhouse of red raspberry genotypes to root rot. HortScience 43:1367-1370.

Jennings, D.L. 1988. Raspberries and blackberries: Their breeding, diseases and growth. Academic Press, San Diego, CA.
Kempler, C., A.M. Muehlchen, and T.A. Forge. 2012. Screening for resistance to Phytophthora root rot in raspberries: Identifying new sources of resistance. Acta Hort. 926: 59-64.

Lévesque, C.A. and H.A. Daubeny. 1999. Variation in reaction to Phytophthora fragariae var. rubi in raspberry genotypes. Acta Hort. 505:231-235.

Lewis, D. 1939. Genetical studies in cultivated raspberries. J. Genet. 38:367-379.

Pattison, J.A., W.F. Wilcox, and C.A. Weber. 2004. Assessing the resistance of red raspberry (Rubus idaeus L.) genotypes to Phytophthora fragariae var. rubi in hydroponic culture. HortScience 39:1553-1556.

Quito-Avila, D.F. and R.R. Martin. 2012. Realtime RT-PCR for detection of Raspberry bushy dwarf virus, Raspberry leaf mottle virus, and characterizing synergistic interactions in mixed infections. J. Virol. Methods 179:38-44. 